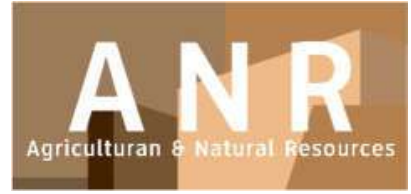

PAPER - OPEN ACCESS

\title{
Perencanaan Ekowisata Di Areal PT ANTAM Tbk, Bogor, Jawa Barat
}

\author{
Author $\quad$ : Ratna Sari Hasibuan dan Ripki Taopik \\ DOI $\quad: 10.32734 /$ anr.v2i1.571 \\ Electronic ISSN : :2654-7023 \\ Print ISSN : :2654-7015
}

Volume 2 Issue 1 - 2019 TALENTA Conference Series: Agricultural and Natural Resources (ANR)

\section{(c) $(1) \Theta$}

This work is licensed under a Creative Commons Attribution-NoDerivatives 4.0 International License.

Published under licence by TALENTA Publisher, Universitas Sumatera Utara 


\title{
tolentinth hionis TALENTA Conference Series
}

Available online at https://talentaconfseries.usu.ac.id

\section{Perencanaan Ekowisata Di Areal PT ANTAM Tbk, Bogor, Jawa Barat}

\author{
(Ecotourism Planning in PT ANTAM Tbk, Bogor, West Java) \\ Ratna Sari Hasibuan ${ }^{1 *}$ dan Ripki Taopik ${ }^{2}$ \\ ${ }^{*}$ Program Studi Kehutanan, Fakultas Kehutanan, Universitas Nusa Bangsa \\ Jalan KH. Sholeh Iskandar KM. 4, Cibadak, Tanah Sereal, Cibadak,Bogor, 16166, Indonesia \\ ${ }^{2}$ PT. ANTAM Tbk UBPE Pongkor Bogor-Indonesia \\ E-mail: ratna@unb.ac.id
}

\begin{abstract}
Abstrak.
Izin Usaha Pertambangan (IUP) PT. ANTAM berdasarkan Keputusan Menteri Pertambangan No.375. K/ 7401/078/2000 berakhir tahun 2020 dengan produk emas. PT. Antam Tbk. menerapkan system pertambangan bawah tanah yaitu dengan menggunakan metode "Cut and Fill". Pasca tambang diharapkan kawasan PT. Antam (Persero) Tbk menjadi tempat wisata. Penelitian ini bertujuan untuk mengidentifikasi potensi ekowisata dan merancang strategi ekowisata. Metode yang digunakan adalah metode deskriptif dan merancang strategi ekowisata dianalisis dengan SWOT analisis. Hasil penelitian adalah potensi ekowisata meliputi Lubang Tambang Gudang Handak dan Taman Buah Cikaret, Peternakan Domba, Curug Cikaret, Air Terjun Ngumpet dan Curug Avan. Berdasarkan identifikasi potensi ekowisata, program ekowisata di wilayah PT. ANTAM adalah "Pongkor tourism" dengan strategi hasil analisis SWOT yang dapat dipilih di kuadran yang merupakan strategi agresif.
\end{abstract}

Kata Kunci : Potensi Ekowisata, analisis SWOT, PT. ANTAM

\begin{abstract}
Mining Business Permit (IUP) PT. ANTAM is based on Minister of Mining Decree No.375. K/7401/078/2000 ends in 2020 with gold products. The mining system implemented by PT. Antam Tbk. is underground mining using the "Cut and Fill" method. Postmining, PT. Antam (Persero) Tbk is a tourist place. This research purpose was to identify the potential of ecotourism and design an ecotourism strategy. The method used was descriptive method and designing ecotourism strategies analyzed by SWOT analysis. The results of the study were the potential of ecotourism including the Mine Hole of Handak Warehouse and Cikaret Fruit Park, Domba Farm, Cikaret Waterfall, Ngumpet Waterfall and Avan Waterfall. Based on the identification of ecotourism potential, ecotourism programs in the PT. ANTAM was "Pongkor tourism" with SWOT analysis strategy that can be selected in the quadrant which was an aggressive strategy.
\end{abstract}

Keywords: Potential Ecotourism, SWOT analysis, PT. ANTAM

(c) 2019 The Authors. Published by TALENTA Publisher Universitas Sumatera Utara

Selection and peer-review under responsibility of Pertemuan Ilmiah Tahunan (PIT) dan Seminar Nasional Ke-4,

Komunitas Manajemen Hutan Indonesia (KOMHINDO)

p-ISSN: 2654-7015, e-ISSN: 2654-7023, DOI: 10.32734/anr.v2i1.571 


\section{Pendahuluan}

"PT. Antam (Persero)Tbk dikelola berdasarkan SK Menteri Pertambangan No. 375 K/7401/078/2000 yang berakhir tahun 2020 dengan luas wilayah eksplorasi 6047 Hektar." Produksi dari PT Antam adalah emas yang merupakan sumberdaya alam yang dapat habis sehingga PT. Antam memiliki harapan kelak pasca tambang Antam dapat melakukan kegiatan ekowisata. Pasca tambang merupakan hal yang harus direncanakan secara matang sehingga tetap menjaga kelestarian alam dan lingkungan sekitar serta mampu meningkatkan kesejahteraan masyarakat Kecamatan Nanggung. Potensi sumberdaya wisata yang ada di wilayah izin usaha pertambangan memiliki berbagai potensi. Potensi tersebut berupa alam, budaya, bangunan, lubang tambang dan lain-lain.

Potensi yang ada perlu direncanakan agar sumberdaya wisata tersebut dapat dimanfaatkan secara lestari dan berkelanjutan serta dapat menarik semakin banyak wisatawan untuk berkunjung, sehingga dapat membantu untuk meningkatkan kesejahteraan masyarakat di Kecamatan Nanggung. Perencanaan ekowisata ini perlu menggunakan media promosi agar masyarakat luas dapat mengetahui dan mendatangi obyek wisata yang berada di Kecamatan Nanggung. Bentuk media promosi yang direncanakan harus menarik sehingga informasi yang diberikan dapat dimengerti oleh semua pihak. Penelitian ini bertujuan untuk mengidentifikasi potensi ekowisata dan merancang strategi ekowisata di areal PT. Antam (Persero) Tbk .

\section{Metode Penelitian}

Penelitian dilakukan di Areal PT. Antam, Kecamatan Nanggung Kabupaten Bogor. Penelitian ini dilakukan mulai bulan September hingga November 2017. Pada penelitian ini menggunakan alat dan bahan seperti alat tulis,kamera,laptop,peta kawasan,dan tally sheet. Penelitian ini menggunakan metode deskriptif yaitu dengan mendeskripsikan hasil identifikasi potensi wisata dengan observasi langsung ke lapangan dan untuk merancang strategi ekowisata yang dianalisa dengan SWOT. "Menurut [1] analisa SWOT adalah mengidentifikasi faktor-faktor penting dengan sistematik sehingga dapat dirumuskan suatu strategi." "Analisis SWOT yang digunakan dengan melihat kondisi sebuah obyek wisata secara sistematik dan membandingkan faktor internal Kekuatan (strengths) dan Kelemahan (weaknesses) dengan faktor eksternal Peluang (opportunities) dan Ancaman (threats)". "Matriks SWOT menggambarkan secara jelas bagaimana peluang dan ancaman eksternal yang dihadapi dilokasi penelitan dan dapat disesuaikan dengan kekuatan dan kelemahan yang dimiliki lingkungan tersebut". Ada empat kemungkinan alternatif yang dihasilkan matriks ini. Selanjutnya, dijumlahkan nilai masing-masing faktor untuk memperoleh nilai IFAS dan EFAS. Keempat strategi tersebut yaitu :

1. SO, yaitu memanfaatkan kekuatan dan peluang yang sebesar-besarnya

2. ST, yaitu memanfaatkan kekuatan yang untuk mengatasi ancaman

3. WO, yaitu memanfaatkan peluang untuk meminimalkan kelemahan yang ada

4. WT, yaitu menghindari ancaman dan meminimalkan kelemahan

\section{Hasil dan Pembahasan}

\subsection{Potensi Ekowisata di Areal PT Antam (Persero) Tbk UBPE Pongkor}

PT. Antam memiliki berbagai potensi yang dapat mendukung diadakannya perencanaan ekowisata di wilayah pertambangan PT Antam. Potensi yang ada dapat dilihat pada Tabel 1. 
Tabel 1. Potensi Ekowisata Di Wilayah PT Antam (Persero) Tbk UBPE Pongkor.

\begin{tabular}{lll}
\hline No & Potensi Ekowista & Uraian \\
\hline A & Lorong Tambang & Wisata tambang bawah tanah (edukasi) \\
& Lubang Tambang Gudang Handak & \\
B & Kawasan Cikaret & Luas 20 Ha untuk wisata edukasi \\
1 & Taman Buah & Curug Cikaret memiliki ketiggian \pm 12 Meter \\
2 & Curug Cikaret & Curug ini memiliki ketinggian \pm 20 Meter \\
3 & Curug Avan & Curug Ngumpet memiliki ketinggian \pm 7 Meter \\
4 & Curug Ngumpet & Budidaya domba garut dapat menjadi sarana edukasi \\
5 & Budidaya Domba & \\
\hline
\end{tabular}

\subsubsection{Lorong Tambang}

Menurut [2], "PT. Antam Tbk memiliki sistem penambangan bawah tanah (Underground Mining ) dengan menggunakan metode "Cut and Fill" yaitu bijih emas diambil dengan mengeruk perut bumi sehingga terbentuk lubang - lubang dan lubang tersebut diisi kembali dengan menggunakan material limbah (waste material) berbentuk lumpur (slurry) yang merupakan limbah hasil pengolahan yang telah bersih dari zat- zat berbahaya". PT. Antam (Persero) Tbk memiliki beberapa lubang tambang salah satunya adalah lubang tambang Gudang Handak. Lubang tambang gudang Handak memiliki lebar 6 meter dan tinggi 4 meter. Terowongan ini berada pada ketinggian sekitar 450 meter. Di dalam lorong terdapat cahaya dari lampu yang dipasang di setiap jarak 20 meter untuk membantu pengunjung mobilisasi di lubang gudang handak. Kegiatan di lubang handak antara lain pengunjung memasuki lubang dan ditemani oleh pendamping yang menjelaskan mengenai gudang handak, pengunjung dapat mengetahui dan merasakan suasana di dalam lubang tambang. Lubang gudang handak difasilitasi dengan blower atau udara sehingga pengunjung tidak merasakan pengap dan panas di dalam lubang. Sepanjang perjalanan diberikan diorama dan papan informasi, museum dan mini theater untuk mengetahui proses edukasi tambang emas bawah tanah.

Lubang tambang di wilayah PT. Antam sangat cocok untuk dijadikan wisata edukasi mengenai proses penambangan emas. Seperti pada hasil penelitian [3] yang menyatakan bahwa pengunjung dan masyarakat sekitar menyetujui dilakukannya pengelolaa wisata di wilayah pertambangan. Namun yang perlu dipertimbangkan adalah pemberian pengetahuan terhadap pengunjung dan melakukan pengelolaan wisata yang baik untuk kedepannya. Lubang tambang di wilayah PT Antam dapat dilihat pada Gambar 1.

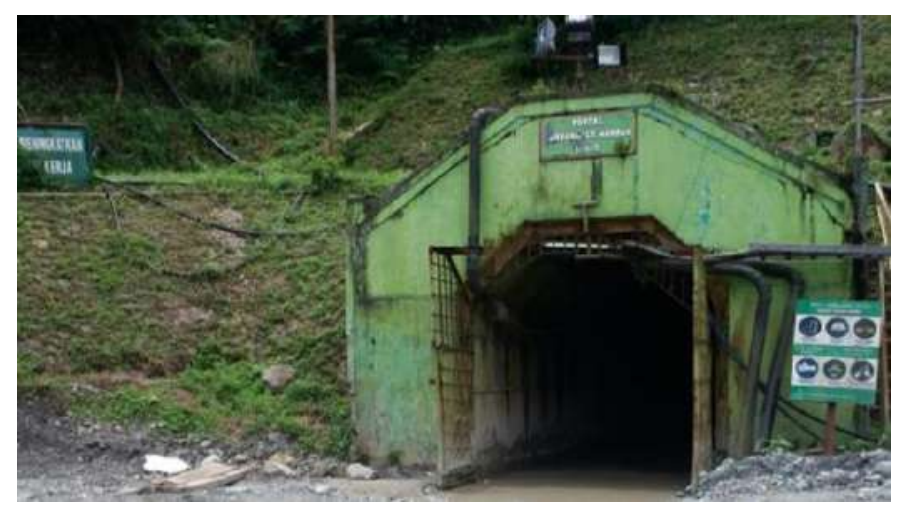

Gambar 1. Lorong Gudang Handak

Rancangan ekowisata tambang diharapkan menjadi daerah tujuan wisata yang berbeda dengan yang lainnya. Lubang tambang dapat menjadi ikon wisata baru di Bogor dan menjadikan lahan kerja baru untuk warga sekitar. Alur untuk kegiatan wisata tambang ini dapat dilihat pada Gambar 2. 


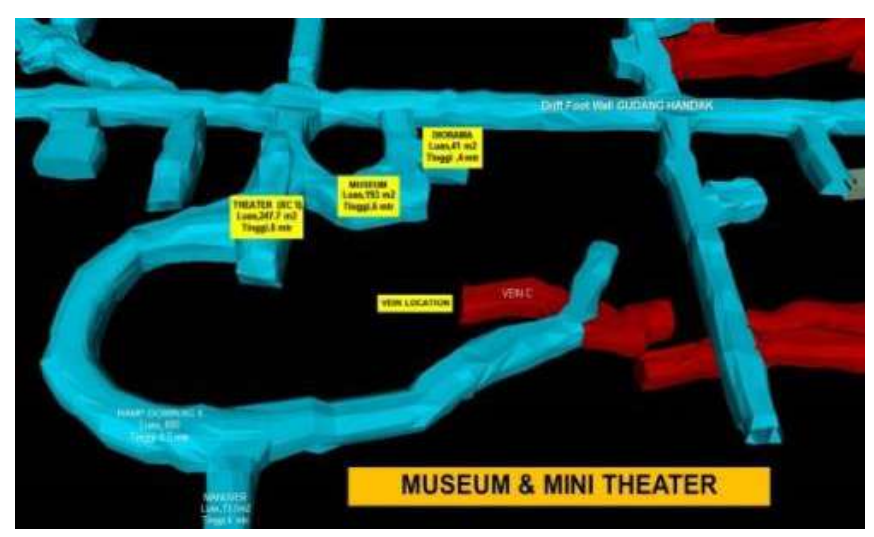

Gambar 2. Alur Wisata Tambang

\subsubsection{Kawasan Cikaret}

Kawasan Cikaret berada di Kampung Cikaret, Desa Bantar Karet, Kecamatan Nanggung. Kawasan Cikaret yang di dalamnya juga terdapat tanaman buah-buahan. Luasan area Taman Buah Cikaret \pm 20 Ha. Cikaret berada pada ketinggian 423-530 mdpl. Jenis tanah di Cikaret yaitu asosiasi latosol coklat dan latosol kekuningan. Rata-rata curah hujan di Cikaret adalah 400-800 mm/tahun dan suhu rata-rata $26-34^{\circ} \mathrm{C}$.

Vegetasi yang dapat ditemukan di Cikaret adalah Jambu Kristal (Psidium guajava), Jambu Jamaica (Syzygium malaccensis), Manggis (Garcinia mangostana L.), Tanaman Pisang (Musaparadisiaca), Bambu (Bambusa arundinaceae), Durian (Duriozibethinus), Kelengkeng (Dimocarpus longan), Sawo (Manilkara zapota), Padi (Oryza sativa), Alpukat (Persea americana), dan Mangga (Mangifera indica). Kawasan PT. Antam terletak berdekatan dengan Taman Nasional Gunung Halimun Salak. Maka tidak jarang satwa seperti burung sering terlihat di kawasan ini. Buahbuahan atau biji-bijian merupakan makanan para satwa terutama burung. Menurut hasil penelitian [4] terdapat 138 jenis burung yang terdapat di wilayah TNGHS, sedangkan menurut [5] keanekaragaman burung yang ditemukan di PT. Aneka Tambang terdiri dari 33 jenis burung dan 9 jenis Mamalia. "Apabila vegetasi yang ada di kawasan PT. Antam mempunyai keanekaragaman yang tinggi, maka dapat menjadi tempat bersarang,berlindung bahkan menjadi tempat sumber pakan berbagai jenis burung ,hal ini sesuai dengan penelitian [6] bahwa pemanfaatan habitat untuk hinggap dan bertengger biasanya dilakukan burung pada pohon-pohon yang tinggi dan besar". Selain manfaat dalam hal ekologi, kehadiran kawasan Cikaret tentu bermanfaat untuk pengelola dan masyarakat sekitar. Kawasan Cikaret dapat menjadi obyek unggulan nantinya jika dikemas menjadi kawasan wisata dengan baik. Jarak dari pusat Kota Bogor 47,5 km dan dari Jakarta 101 km. Kawasan Cikaret dapat dilihat pada Gambar 3.

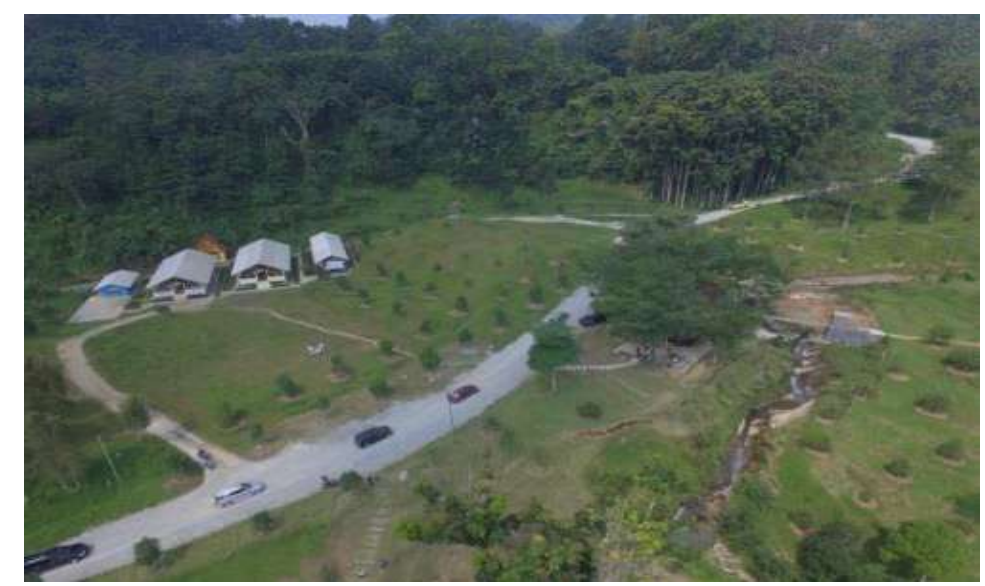

Gambar 3. Taman Buah Cikaret Sumber : PT Antam Tbk (2017) 


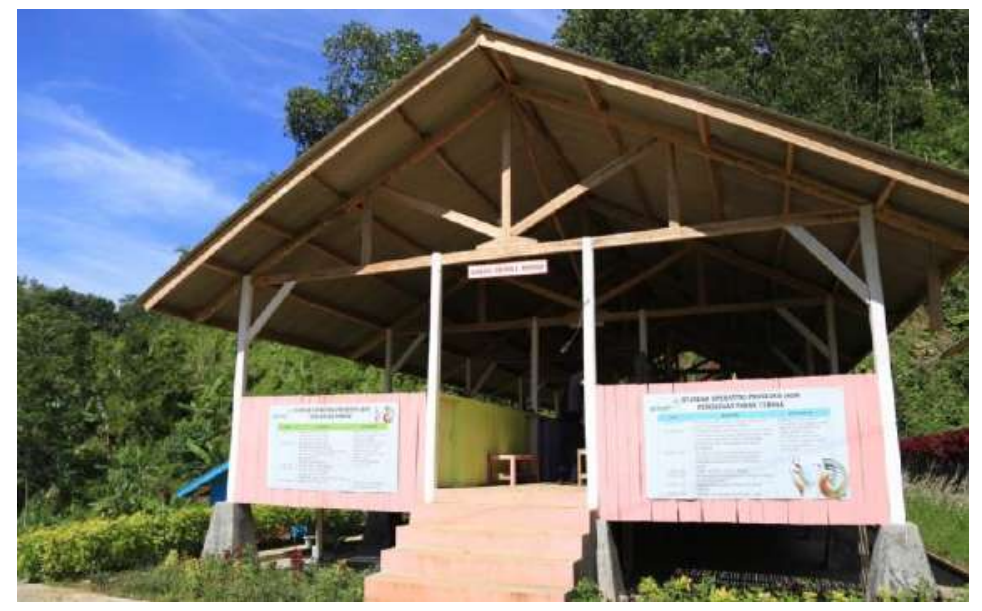

Gambar 4. Kandang Domba

Kawasan Cikaret tidak hanya terdapat tanaman buah saja tetapi terdapat budidaya domba (Gambar 4), sungai, dan curug. Sungai yang terdapat di Cikaret adalah Sungai Cipamangon dan Sungai Cipanas. Aliran sungai tersebut mengaliri 3 buah air terjun (curug) yang terdapat di Cikaret. Air terjun yang terdapat di Cikaret yaitu Curug Ngumpet (Gambar 5), Curug Cikaret (Gambar 6) dan Curug Avan.

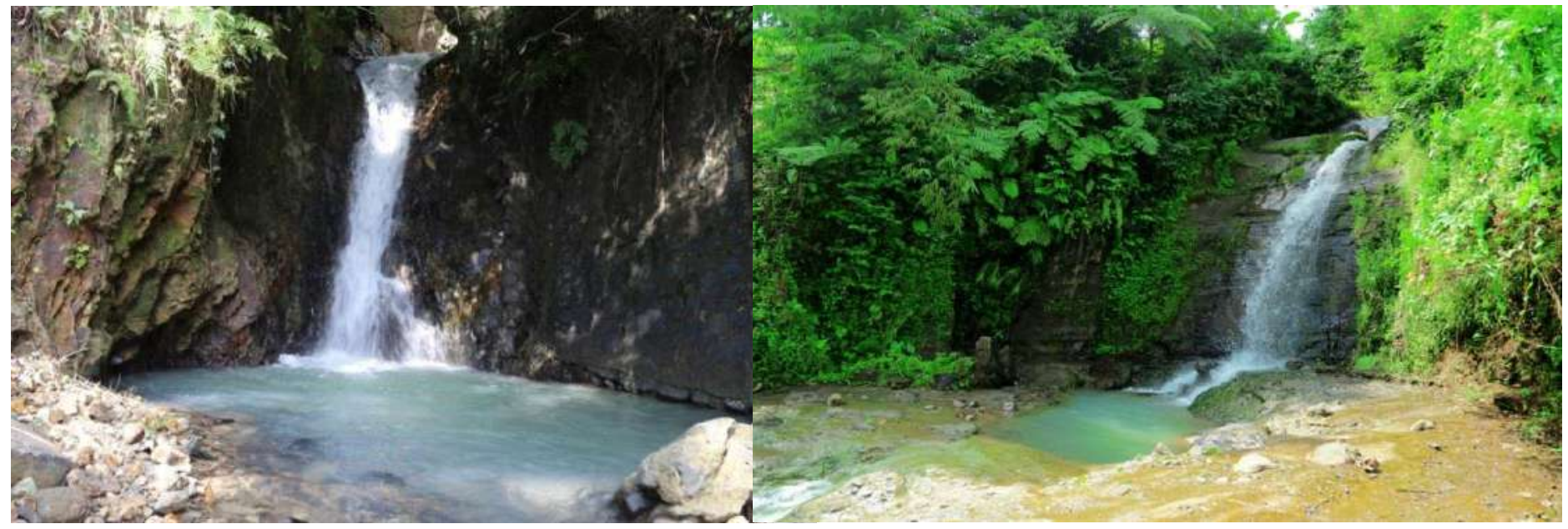

Gambar 5. Curug Ngumpet

Gambar 6. Curug Cikaret

\subsection{Menyusun Rencana Program Ekowisata}

Potensi yang telah diperoleh dari proses identifikasi dan observasi lapangan dapat diuraikan dalam bentuk program ekowisata dan media promosi.

\subsubsection{Program Ekowisata}

Pesan yang ingin disampaikan kepada pengunjung dapat diuraikan dalam bentuk program interpretasi ataupun program ekowisata [7]. Program tersebut dibuat dapat berupa urutan-urutan kegiatan sesuai dengan lokasi yang akan dibuat sebagai areal wisata. Berdasarkan hasil identifikasi potensi wisata maka program ekowisata di areal PT. ANTAM adalah "Pongkor tourism". Program ini dapat menarik minat wisatawan untuk merasakan suasana pertambangan dan alam di lingkungan PT Antam. Selain mengunjungi lubang tambang pengunjung juga akan dibawa ke kawasan wisata Cikaret untuk merasakan kesegaran alam setelah masuk ke dalam lubang tambang. Ittinerary kegiatan disajikan pada Tabel 2, sedangkan rangkaian kegiatan Pongkor Tourism dapat dilihat pada Gambar 7. 
Tabel 2. Ittinerary Kegiatan Pongkor Tourism

\begin{tabular}{ll}
\hline Nama Kegiatan & Waktu \\
\hline Berkumpul di Area Admin PT Antam & $08.00-08.30$ \\
Perkenalan dan Safety Induction & $08.30-09.30$ \\
Persiapan Pemakaian Perlengkapan Safety & $09.30-10.00$ \\
Kunjungan Ke Tambang Gudang Handak & $10.00-11.00$ \\
Kembali ke Admin Untuk persiapan ISHOMA & $11.00-11.30$ \\
ISHOMA & $11.30-13.00$ \\
Persiapan Kunjungan Ke Kawasan Cikaret & $13.00-13.30$ \\
Kunjungan Di Kawasan Cikaret & $13.30-15.00$ \\
Foto Bersama & $15.00-15.15$ \\
Kembali ke Admin & $15.15-15.30$ \\
Istirahat dan Sholat & $15.30-16.00$ \\
Penutupan & $16.00-16.30$ \\
\hline
\end{tabular}

Induction

(Admin Office)

Cikaret Park

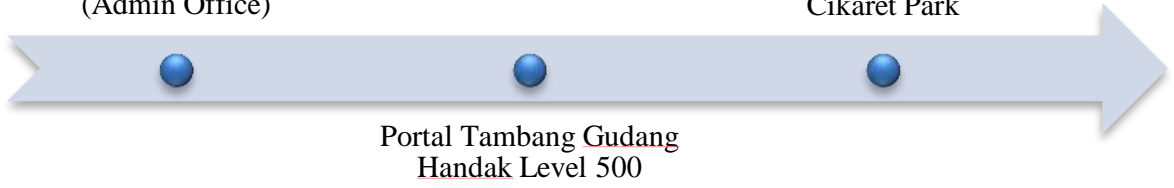

Gambar 7. Rangkaian Kegiatan Pongkor Tourism

Pengunjung yang akan melakukan kegaitan di kawasan PT Antam harus mengikuti safety induction. Safety induction ini merupakan kegiatan yang sangat penting karena pengunjung akan diberi tahu perihal aturan selama mengikuti kegiatan dan pengetahuan awal mengenai wilayah dan potensi di PT Antam. Semua perlengkapan safety sudah disediakan oleh pengelola sehingga pengunjung tinggal menggunakan perlengkap tersebut (Gambar 8). Peralatan khusus yang dipakai adalah:

1. Baju wearpack

2. Safety boot shoes

3. Safety helmet

4. Mine spot lamp (MSL)/lampu tambang

5. Ear protection/pelindung telinga

6. Kacamata pengaman/googles

7. Sarung tangan/gloves

8. Masker/pelindung hidung/pernafasan 


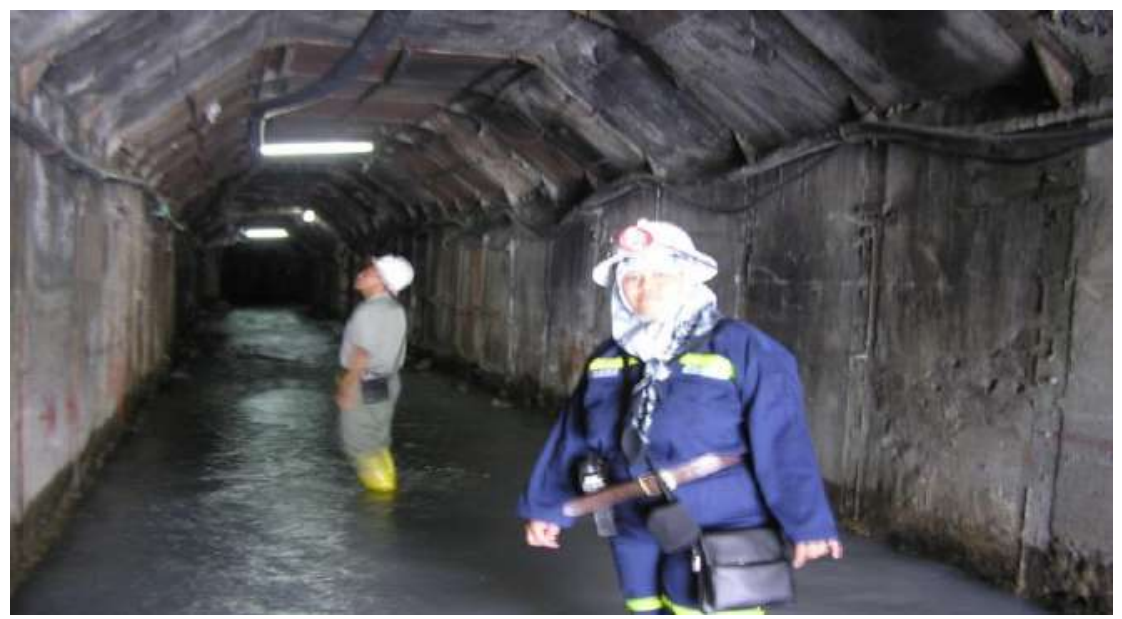

Gambar 8. Perlengkapan Safety Pengunjung

\subsubsection{Rancangan Media Promosi}

"Agar wisatawan tertarik datang kesuatu tempat wisata, maka media promosi adalah hal yang sangat penting, selain itu kerjasama dengan komunitas pelaku pariwisata tentunya sangat berguna untuk memajukan tempat wisata tersebut [8]". Media promosi terdapat berbagai bentuk antara lain dapat berupa visual, audio, dan audio visual. Untuk media promosi secara visual yang dirancang adalah berupa leaflet. Leaflet ini terdiri dari 2 halaman yaitu depan dan belakang yang berisikan informasi mengenai potensi yang terdapat di wilayah PT Antam Tbk. Rancangan Leaflet dapat dilihat pada Gambar 9.
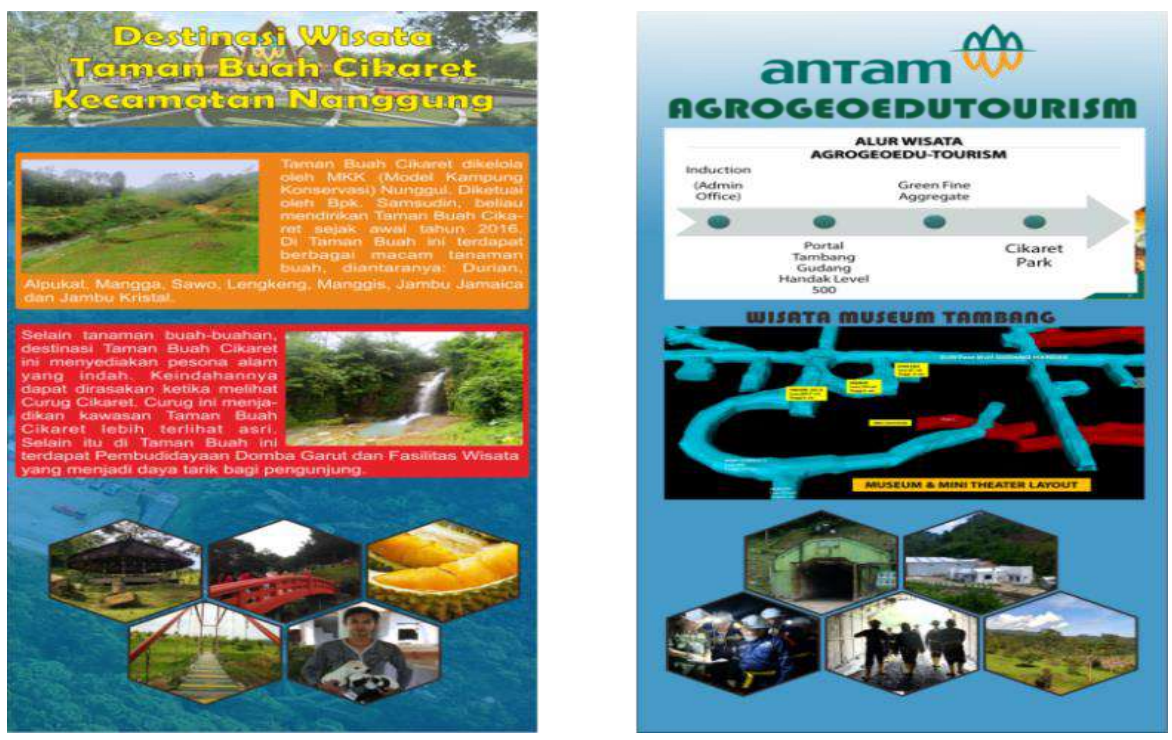

Gambar 9. Media Promosi Berupa Leaflet

\subsection{Strategi Ekowisata}

Strategi Ekowisata dilakukan dengan menggunakan analisa SWOT. Berdasarkan hasil penelitian diperoleh faktorfaktor internal dan eksternal. Kekuatan dan kelemahan merupakan faktor internal sedangkan peluang dan ancaman merupakan faktor eksternal, hal ini dapat dilihat pada Tabel 3. 
Tabel 3. Faktor Internal dan Eksternal di Wilayah PT. Antam Tbk

\begin{tabular}{ll}
\hline Kekuatan $($ strength) & Kelemahan (weakness) \\
\hline -Keindahan dan daya tarik wisata di Wilayah PT Antam & -Belum ada fasilitas wisata \\
-Persiapan Pasca Tambang & -Konflik ruang dengan penambang liar \\
-Banyak potensi yang belum tereksplore & -Adanya persengketaan tanah \\
-Rencana kerjasama dengan pihak ketiga & -Belum adanya pengelolaan wisata \\
-Aksesibilitas mudah dijangkau & -Jarak Tempuh \\
\hline Peluang (Oppotunity) & Ancaman (threat) \\
\hline -Lokasi strategis dalam perencanaan Bogor Barat & -Persaingan dengan kawasan wisata populer \\
-Potensi sebagai objek wisata ikonik & -Penambang emas liar \\
-Kebijakan pemerintah daerah dalam pengembangan sektor wisata & -Pencemaran lingkungan \\
-Didukung oleh potensi wisata di desa sekitar Antam & -Belum adanya izin wisata \\
-Besarnya minat masyarakat & -Kemerosotan Moral Sosial \\
\hline
\end{tabular}

\subsubsection{Analisis Faktor Internal dan Eksternal dalam Perencanaan Ekowisata di Wilayah Antam Pongkor}

\subsubsection{Matriks Evaluasi Faktor Internal}

Skor kekuatan (strength) dan kelemahan (weakness) yang merupakan faktor-faktor internal PT Antam yang diperoleh berdasarkan hasil penelitian dapat dilihat pada Tabel 4. Selanjutnya, skor-skor tersebut dijumlahkan sehingga memperoleh nilai IFAS dan EFAS.

Tabel 4. Matriks Evaluasi Faktor Internal

\begin{tabular}{ll}
\hline Kekuatan (strength) & Skor \\
\hline Keindahan dan daya tarik wisata di Wilayah PT Antam & 0,4 \\
Persiapan Pasca Tambang & 0,4 \\
Banyak potensi yang belum tereksplore & 0,3 \\
Rencana kerjasama dengan pihak ketiga & 0,4 \\
Aksesibilitas mudah dijangkau & 0,4 \\
\hline Total Kekuatan & $\mathbf{1 , 9}$ \\
\hline Belum ada fasilitas wisata & 0,2 \\
Konflik ruang dengan penambang liar & 0,3 \\
Adanya masalah persengketaan tanah & 0,2 \\
Belum adanya pengelolaan wisata & 0,2 \\
Jarak Tempuh & 0,2 \\
Total Kelemahan & $\mathbf{1 , 1}$ \\
Total kekuatan - Total kelemahan = S-W & $\mathbf{0 , 8}$ \\
\hline
\end{tabular}

\subsubsection{Matriks Evaluasi Faktor Eksternal}

Peluang dan Ancaman merupakan faktor eksternal dalam penelitian ini. Evaluasi faktor eksternal dilakukan dengan cara yang sama dengan perumusan yang dapat dilihatpada Tabel 5. 
Tabel 5. Matriks Evaluasi Faktor Eksternal

\begin{tabular}{ll}
\hline Peluang (Opportunity) & Skor \\
\hline Lokasi strategis dalam perencanaan bogor barat & 0,4 \\
Potensi sebagai objek wisata ikonik & 0,3 \\
Kebijakan pemerintah daerah dalam pengembangan sektor wisata & 0,27 \\
Didukung oleh potensi wisata di desa sekitar Antam & 0,27 \\
Besarnya minat masyarakat & 0,44 \\
Total Peluang & $\mathbf{1 , 6 8}$ \\
\hline Ancaman (Threat) & $\mathbf{S k o r}$ \\
\hline Persaingan dengan kawasan wisata popular & 0,22 \\
Penambang emas liar & 0,3 \\
Pencemaran lingkungan & 0,3 \\
Belum adanya izin wisata & 0,2 \\
Kemerosotan Moral Sosial & 0,3 \\
\hline Total & $\mathbf{1 , 3 2}$ \\
\hline Total peluang - Total ancaman = O-T & $\mathbf{0 , 3 6}$ \\
\hline
\end{tabular}

Perhitungan Terhadap faktor-faktor internal dan ekternal kemudian dijumlahkan untuk menentukan alternatif strategi. Berdasar hasil penelitian diperoleh strategi Weakness-Opportunity, strategi Weakness-Threat, strategi Strength-Opportunity dan strategi Strength-Threat. Hasil perhitungan yang sudah dilakukan maka dapat diketahui bahwa nilai total skor IFAS $=\mathbf{0 , 8}$ dan nilai total skor EFAS =0,36 sehingga diketahui posisi perencanaan ekowisata di wilayah PT Antam berada pada kuadran I (S-O) yaitu strategi Agresif. Posisi perencanaan ekowisata di wilayah PT Antam disajikan pada Gambar 10.

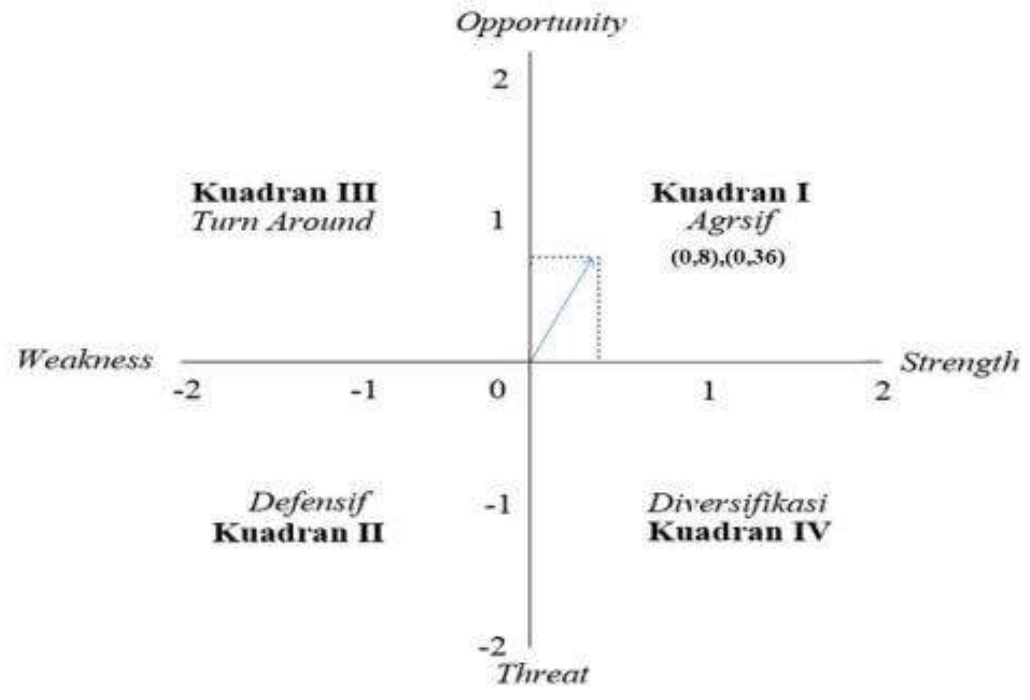

Gambar 10. Posisi Kuadran

\subsubsection{Strategi Perencanaan Ekowisata di Wilayah PT. Antam Tbk}

Perhitungan yang dilakukan dengan menggunakan metode SWOT maka diperoleh strategi perencanaan ekowisata di wilayah PT Antam. Metode SWOT digunakan untuk melihat potensi yang terdapat di wilayah Antam baik internal maupun eksternal. Startegi SO (Strength Opportunity) yang ditemukan berdasarkan hasil penelitian. Strategi SO digunakan dengan memaksimalkan kekuatan internal yang dimiliki oleh PT.Antam dan dengan memanfaatkan peluang yang ada, seperti keindahan alam flora dan fauna yang dimiliki, dimana PT. Antam berdekatan dengan Taman Nasional Halimun Salak dan juga akses yang mudah dicapai serta programini sangat didukung oleh pemerintah kabupaten Bogor.

PT Antam yang terletak bersebelahan dengan Taman Nasional Gunung Halimun Salak sehingga memiliki potensi sumberdaya alam yang sangat menarik dan kekayaan flora fauna sehingga perlu diidentifikasi dan dikelola secara bijak. Perencanaan ekowisata dapat memaksimalkan potensi tersebut sehingga dapat meningkatkan pendapatan 
masyarakat sekitar. Obyek yang menjadi ikonik di PT Antam adalah Cikaret dan lubang tambang. Kawasan Cikaret dapat menjadi wisata keluarga dan untuk wisata tambang dapat menjadi wisata minat khusus yang bertema edukasi.

Hasil analisa data SWOT maka alternatif strategi yang digunakan adalah berdasar skor faktor internal dan faktor eksternal. Hasil Tabel 4 dan 5 yang merupakan hasil perhitungan faktor internal dan eksternal, dengan nilai total skor $I F A S=0,8$ dan $E F A S=\mathbf{0 , 3 6}$ maka hasil yang diperoleh pada kuadran satu (I) $[(\mathbf{0 , 8}),(\mathbf{0 , 3 6})]$ yaitu strategi Agresif. Strategi ini harus digunakan PT. Antam yaitu dengan memanfaatkan peluang dan kekuatan yang ada (Growth oriented strategy).

\section{Kesimpulan}

Potensi ekowisata yang berada di wilayah PT Antam Tbk di antaranya Lubang Tambang Gudang Handak dan Taman Buah Cikaret, Budidaya Domba, Curug Cikaret, Curug Ngumpet dan Curug Avan. Berdasarkan hasil identifikasi potensi ekowisata maka program ekowisata di areal PT. ANTAM adalah "Pongkor tourism" dengan strategi hasil analisa SWOT yang dapat dipilih berada pada kuadran satu (I) $[(0,8),(0,36)]$ yaitu strategi Agresif.

\section{Ucapan Terima Kasih}

Ucapan terima kasih dan penghargaan kepada:

1. Manajemen PT Antam (Persero) Tbk yang telah memberikan rekomendasi dan ijin kepada penulis untuk melakukan penelitian.

2. Masyarakat Desa Bantarkaret Kecamatan Nanggung yang banyak membantu penulis dalam menyelesaikan penelitian ini.

\section{Referensi}

[1] Rangkuti F, "Analisis SWOT Teknik Membedah Kasus Bisnis". Jakarta : PT. Gramedia Pustaka Umum, 2009".

[2] M. B. A. Siallagan, "Emas Di Gunung Pongkor ( Studi Kasus: Desa Cisarua , Malasari , dan Bantarkaret di Kecamatan Nanggung, Kabupaten Bogor )," [Skripsi]. Bogor (ID): Institut Pertanian Bogor, 2010.

[3] Kurniawati E, "Persepsi Pengunjung Terhadap Objek Wisata Lubang Tambang Mbah Soero Di Kota Sawahlunto Sumatera Barat," J. Jom Fisip, vol. 2, no. 1, pp. 1-14, 2015.

[4] Wisnubudi G, "Penggunaan Strata Vegetasi Oleh Burung Di Kawasan Wisata Taman NasionalGunung HalimunSalak," J. VIS VITALIS, vol. 02, no. 2, pp. 41-49, 2009.

[5] Hasibuan RS et al, "Keanekaragaman Burung Dan Mamalia Pada Lahan Reklamasi PT. Aneka Tambang, Bogor Jawa Barat," J. Ekol., vol. 18, no. 1, 2018.

[6] Hasibuan RS et al, "Keanekaragaman Jenis Burung Di Resort Tapos Taman Nasional Gunung Gede Pangrango," in SenasPro 2 Seminar Nasional Dan Gelar Produk Universitas Muhamadiah Malang, 2017, pp. 16-24.

[7] Hasibuan RS et al, "Jalur Interpretasi "BIRDWATCHING” Di Kebun Raya Bogor," Media Konserv., vol. 23 , no. $1,2018$.

[8] V. D. Wardhani RS, “Green Tourism Dalam Pengembangan Pariwisata Bangka Belitung," in Prosiding Seminar Nasional INDOCOMPAC, 2016. 